Original

\title{
Effect of hypoxia on the expression of CCAAT/enhancer- binding protein $\beta$ and receptor activator of nuclear factor kappa-B ligand in periodontal ligament cells
}

\author{
Hisanori Ito'), Takashi Kifune1), Misa Ishiyama1), Satoko Iwasa1), Hiroki Takei1), \\ Tomokazu Hasegawa'2), Masatake Asano ${ }^{3)}$, and Tetsuo Shirakawa ${ }^{1,4)}$ \\ 1)Department of Pediatric Dentistry, Nihon University School of Dentistry, Tokyo, Japan \\ 2)Department of Pediatric Dentistry, Tokushima University Hospital, Tokushima, Japan \\ 3)Department of Pathology, Nihon University School of Dentistry, Tokyo, Japan \\ 4)Division of Oral and Craniomaxillofacial Research, Dental Research Center, \\ Nihon University School of Dentistry, Tokyo, Japan
}

(Received November 16, 2017; Accepted December 22, 2017)

\begin{abstract}
Hypoxia after traumatic injuries to a tooth is one of the causes of subsequent root resorption. Inflammatory cytokines produced under hypoxic conditions are associated with root resorption, but the mechanism has not been fully understood. In this study, the role of hypoxia-inducible factor-1 (HIF-1) signaling in the regulation of CCAAT (cytosine-cytosine-adenosine-adenosine-thymidine)/ enhancer-binding protein- $\beta$ (C/EBP $\beta)$ and the receptor activator of nuclear factor kappa-B ligand (RANKL) expressions in immortalized human periodontal ligament (PDL) cells was investigated. PDL cells cultured under a hypoxic condition showed an increase in the expression of C/EBP 3 and RANKL messenger RNAs (mRNAs), whereas the expression of osteoprotegerin and HIF-1a mRNAs was unaffected. Hypoxia had no effects on the secretion of interleukin (IL)-1ß, IL-6, IL-8, IL-17A, tumor necrosis factor-alpha, macrophage migration inhibitory factor, monocyte chemoattractant protein-1, and macrophage colony-stimulating factor in the
\end{abstract}

Correspondence to Dr. Tetsuo Shirakawa, Department of Pediatric Dentistry, Nihon University School of Dentistry, 1-8-13 KandaSurugadai, Chiyoda-ku, Tokyo 101-8310, Japan

Fax: 81-3-3219-8353 E-mail: shirakawa.tetsuo@nihon-u.ac.jp

Color figures can be viewed in the online issue at J-STAGE.

doi.org/10.2334/josnusd.17-0436

DN/JST.JSTAGE/josnusd/17-0436 culture media. Treatment of the cells with dimethyloxaloylglycine, a competitive HIF prolyl hydroxylase inhibitor, significantly increased the expression of $\mathrm{C} /$ EBP $\beta$ and RANKL mRNAs. This suggested that the hypoxia-induced elevation of C/EBP $\beta$ and RANKL mRNAs was dependent on the HIF-1 activity. PDL cells transfected with a specific small interfering RNA designed to target the C/EBP $\beta$ gene showed a significant suppression of the RANKL mRNA. These findings indicated that $\mathrm{C} / \mathrm{EBP} \beta$ may play an important role in tooth root resorption via RANKL activation in hypoxia-exposed PDL cells.

Keywords: periodontal ligament cells; hypoxia; HIF-1; C/EBP $\beta$; RANKL.

\section{Introduction}

The periodontal ligament (PDL) is located between the alveolar bone and the cementum of the tooth root (1). It is well known that root resorption occurs in deciduous teeth but not in permanent teeth under physiological conditions. However, both deciduous and permanent teeth show root resorption under a pathological condition such as traumatic dislocation of a tooth $(2,3)$. In some cases, root resorption after trauma is resistant to conservative treatment, and it eventually results in loss of the tooth (4). Previous reports suggest that the progression of the root resorption is closely related to a change in the activity of 
fibroblastic cells localized in the PDL $(5,6)$.

The receptor activator of nuclear factor kappa-B ligand (RANKL), a polypeptide ligand for osteoprotegerin $(\mathrm{OPG})$, is a member of the tumor necrosis factor (TNF) family of cytokines and promotes differentiation and activation of osteoclasts (7-11). Mature osteoclasts, also known as multinuclear giant cells differentiated from hematopoietic progenitor cells, are capable of resorbing cementum, dentin, and bone $(3,7,9,11)$. The RANKL expression in stromal cells is promoted under inflammatory conditions that are accompanied, in general, by expressions of various cytokines such as interleukin (IL)$1 \beta$, IL-6, IL-8, IL-17 A, TNF- $\alpha$, monocyte chemoattractant protein-1 (MCP-1), and macrophage colony-stimulating factor (M-CSF) (12-17).

Hypoxia induces complex cellular responses that are mediated by a key transcription factor hypoxia-inducible factor-1 (HIF-1) at the early phase of hypoxia-related signal transmission cascade. Recently, the effects of hypoxia on the expression of RANKL were examined in human PDL cells, and an increase in the expressions of RANKL messenger RNA (mRNA) and protein under hypoxia was demonstrated (18-20). HIF-1 $\alpha$ binding to the RANKL promoter was increased under hypoxic conditions, and an overexpression of constitutively active HIF- $1 \alpha$ increased RANKL promoter activity in PDL cells (18). However, it is unknown whether the up-regulation of RANKL production during hypoxia is solely dependent on the direct action of HIF-1 $\alpha$ on the RANKL promoter.

Cytosine-cytosine-adenosine-adenosine-thymidine (CCAAT)/enhancer-binding protein- $\beta(\mathrm{C} / \mathrm{EBP} \beta)$ was first identified as a nuclear protein that bound to the IL-1 response element in the IL-6 promoter region (21). C/ EBP $\beta$ is a member of the C/EBP family of transcription factors and is involved in osteoclast formation by regulating RANKL expression in fibroblast-like synoviocytes in patients with rheumatoid arthritis (22). At present, it is unknown whether $\mathrm{C} / \mathrm{EBP} \beta$ is implicated in the activation of RANKL in PDL cells, and the relationship between the HIF- $1 \alpha$ activity and C/EBP $\beta$ expression in PDL cells is not understood. The objective of this study was to investigate the molecular mechanisms underlying the expression of RANKL in immortalized human PDL cells exposed to hypoxia and to clarify the role of $\mathrm{C} / \mathrm{EBP} \beta$ in the HIF-1 signaling pathway.

\section{Cell line and cell culture}

\section{Materials and Methods}

Immortalized PDL cells (23) derived from human deciduous teeth (SH9 cells) were seeded onto $100 \mathrm{~mm}$ cell culture dishes at $1.0 \times 10^{6}$ cells/dish and maintained at subconfluency in $\alpha$-MEM (minimum essential medium) (WAKO, Tokyo, Japan) supplemented with $10 \%$ fetal bovine serum (FBS, Gibco, Carlsbad, CA, USA) at $37^{\circ} \mathrm{C}$ in a humidified atmosphere of $5 \% \quad \mathrm{CO}_{2} / 95 \%$ air (normoxic condition). For mRNA experiments and western blotting, the cells were seeded onto six-well dishes at $5.0 \times 10^{5}$ cells/well, and for small interfering RNA (siRNA) transfection experiments, the cells were seeded onto 24 -well dishes at $1.0 \times 10^{5}$ cells/well. Hypoxia was induced by transferring the cell culture dishes into an airtight jar containing AnaeroPack-Kenki 5\% (Mitsubishi Gas Chemical, Tokyo, Japan), a disposable $\mathrm{O}_{2}$-absorbing and $\mathrm{CO}_{2}$-generating agent, to reduce the $\mathrm{O}_{2}$ concentration to less than $0.1 \%$ and to keep the $\mathrm{CO}_{2}$ concentration at approximately $5 \%$ (hypoxic condition) (24). The jar was placed in an incubator and kept at $37^{\circ} \mathrm{C}$.

\section{Quantitative reverse transcription polymerase chain reaction (RT-qPCR) analysis}

Total RNA was isolated from PDL cells cultured under either a normoxic or hypoxic condition for $24 \mathrm{~h}$ with the use of RNeasy mini kit (QIAGEN, Hilden, Germany). RNA quality and concentration were assayed using a NanoDrop 2000 device (Thermo Fisher Scientific, Waltham, MA, USA). Purified total RNA was reversetranscribed into cDNA by incubating with Recombinant ribonuclease Inhibitor (TaKaRa Bio, Tokyo, Japan), 5× Prime Script Buffer (TaKaRa Bio), $5 \times$ Reverse Transcriptase M-MLV Buffer (TaKaRa Bio), and Random Primer (Invitrogen, Carlsbad, CA, USA). RT-qPCR assay was performed with SYBR Premix Ex Taq II (TaKaRa Bio), and data analysis was carried out with the use of CFX96Real-Time System (Bio-Rad, Hercules, CA, USA). For quantification of mRNA, the target expression level was normalized to the $\beta$-actin mRNA level. The primer sequences used for RT-qPCR are shown in Table 1.

\section{Cytokine array analysis}

Cytokines secreted into the medium from the cultured PDL cells were analyzed using Human XL Cytokine Array Kit (R\&D Systems, Minneapolis, MN, USA). Conditioned medium was collected after $24 \mathrm{~h}$ incubation under either a normoxic (control) or hypoxic condition and mixed with the reagents included in the assay kit. The mixed solution was reacted with the nitrocellulose membrane on which antibodies against cytokines had been spotted. After an overnight incubation at $4^{\circ} \mathrm{C}$, the membrane was washed and reacted with Chemi Reagent Mix for $1 \mathrm{~min}$. Then, the protein signals on the membrane 
Table 1 Primer sequences used for quantitation of gene expressions

\begin{tabular}{|c|c|c|c|}
\hline Gene & & Sequences (F; forward, R; reverse) & Genbank number \\
\hline \multirow[t]{2}{*}{$\beta$-actin } & F & 5' TGG CAC CCA GCA CAA TGA A 3' & NM_001101.4 \\
\hline & $\mathrm{R}$ & 5' CTA AGT CAT AGT CCG CCT AGA AGC A 3' & \\
\hline \multirow[t]{2}{*}{$I L-6$} & $\mathrm{~F}$ & 5’ ATG TAG CCG CCC CAC ACA GA 3' & NM_000600.4 \\
\hline & $\mathrm{R}$ & 5’ ATG GGT GAA AAT CAT CCT G 3' & \\
\hline \multirow[t]{2}{*}{ MIF } & $\mathrm{F}$ & 5' GCG CCT GCG CAT CAG 3' & NM_002415.1 \\
\hline & $\mathrm{R}$ & 5' CGC GTT CAT GTC GTA ATA GTT GA 3' & \\
\hline \multirow[t]{2}{*}{$T N F-\alpha$} & $\mathrm{F}$ & 5’ CTG CCT GCT GCA CTT TGG AG 3’' & NM_000594.3 \\
\hline & $\mathrm{R}$ & 5’ ACA TGG GCT ACA GGC TTG TCA CT 3' & \\
\hline \multirow[t]{2}{*}{ RANKL } & $\mathrm{F}$ & 5’ CGG GGT GAC CTT ATG AAA CTG 3' & NM_003701.3 \\
\hline & $\mathrm{R}$ & 5' CCA GGG AAT TTA CAA AGT GCA CC 3' & \\
\hline \multirow[t]{2}{*}{$O P G$} & $\mathrm{~F}$ & 5’ TTG AAA TGG CAG TTG ATT CCT T 3’ & NM_002546.3 \\
\hline & $\mathrm{R}$ & 5' TAT CCT CTC TTT CTC AGG GTG CTT 3' & \\
\hline \multirow[t]{2}{*}{ HIF-1a } & $\mathrm{F}$ & 5' GTC TCG AGA TGC AGC CAG AT 3' & NM_001243084.1 \\
\hline & $\mathrm{R}$ & 5' TCA CCA GCA TCC AGA AGT TTC 3' & \\
\hline \multirow[t]{2}{*}{$C / E B P \beta$} & $\mathrm{F}$ & 5’ AGT ACA AGA TCC GGC GCG AG 3' & NM_001285878.1 \\
\hline & $\mathrm{R}$ & 5' TGC TTG AAC AAG TTC CGC AG 3' & \\
\hline
\end{tabular}

were visualized using Universal Hood II (Bio-Rad). The expression level of each cytokine was digitized with image analysis software (ImageQuant TL, GE Healthcare Life Sciences, Pittsburgh, PA, USA).

\section{Western blotting}

Whole-cell lysates of the PDL cells were prepared after the $24 \mathrm{~h}$ incubation under either a normoxic (control) or hypoxic condition. Equal amounts of protein (30 $\mu \mathrm{g}$ : total protein) were fractionated by sodium dodecyl sulfate-polyacrylamide gel electrophoresis and subsequently transferred to Immobilon polyvinylidene difluoride membranes (Merck, Darmstadt, Germany). The membranes were blocked for $1 \mathrm{~h}$ in $1 \%$ bovine serum albumin (BSA)-phosphate-buffered saline (PBS) with Tween-20. Then, the membranes were incubated overnight at $4^{\circ} \mathrm{C}$ with a rabbit anti-HIF $1 \alpha$ antibody $(\times 1,000)$ (Novus Biologicals, Littleton, CO, USA), a rabbit anti-RANKL antibody $(\times 1,000)$ (Abcam, Cambridge, UK), or a rabbit anti- Glyceraldehyde 3-phosphate dehydrogenase $($ GAPDH) antibody $(\times 1,000)$ (Santa Cruz Biotechnology, Dallas, TX, USA), followed by incubation with a horseradish peroxidase-conjugated goat anti-rabbit $\operatorname{IgG}(\mathrm{H}+\mathrm{L})$ secondary antibody $(\times 10,000)$ (Jackson Immuno Research, West Grove, PA, USA) for $1 \mathrm{~h}$ at room temperature (RT). GAPDH served as the internal control. Specific protein bands on the membrane were detected using Western ELC Substrate (Bio-Rad), and the intensity was digitized with ImageQuant TL software.

\section{Immunofluorescence staining}

PDL cells were seeded on a chamber slide (Lab-Tek Chamber Slide; Thermo Fisher Scientific) at $2.5 \times 10^{4}$ cells/dish. Subconfluent PDL cell monolayers were cultured under either normoxic or hypoxic condition for $24 \mathrm{~h}$. The cell monolayers were fixed for $10 \mathrm{~min}$ at RT with 2\% paraformaldehyde in PBS, permeabilized for $10 \mathrm{~min}$ at RT with $1 \%$ Triton-X100 diluted in PBS, blocked for 30 min at RT with $1 \%$ BSA-PBS, and incubated with a solution containing a rabbit anti-RANKL antibody $(\times 100)$ (Abcam) and a rabbit polyclonal HIF- $1 \alpha$ antibody $(\times 100)$ (Novusbio, Littleton, CO, USA) for $12 \mathrm{~h}$ at $4^{\circ} \mathrm{C}$. The cell monolayers were incubated for $60 \mathrm{~min}$ at RT with the secondary antibodies. The secondary antibodies used were Alexa Fluor 568 conjugated goat anti-rabbit IgG $(1: 1,000$; Invitrogen) and Alexa Fluor 488 conjugated goat anti-rabbit $\operatorname{IgG}(1: 1,000$; Invitrogen). The stained cell monolayers were coverslipped with Fluoroshield Mounting Medium with 4',6-diamidino-2-phenylindole (DAPI; Abcam) containing DAPI and imaged using a fluorescence microscope (Nikon Instruments, Tokyo, Japan) equipped with a $20 \times$ objective and a CCD (ChargeCoupled Device) camera. Acquired 24-bit images were analyzed with image processing tools provided by a morphometric image analysis software (Image-Pro Plus Version 7.0; Media Cybernetics, Bethesda, MD, USA). The areas corresponding to the nucleus and cytoplasm in each cell on the slide were selected manually, and the mean fluorescence intensity within the areas was calculated with the software.

\section{HIF-1 $\alpha$ stabilization with dimethyloxaloylglycine (DMOG)}

To evaluate the influence of HIF-1 $\alpha$ on the expression of $\mathrm{C} / \mathrm{EBP} \beta$ in PDL cells, the cells were cultured in $\alpha$-MEM supplemented with $1 \mathrm{mM}$ DMOG (Enzo Life Sciences, Farmingdale, NY, USA), a competitive inhibitor of prolyl 

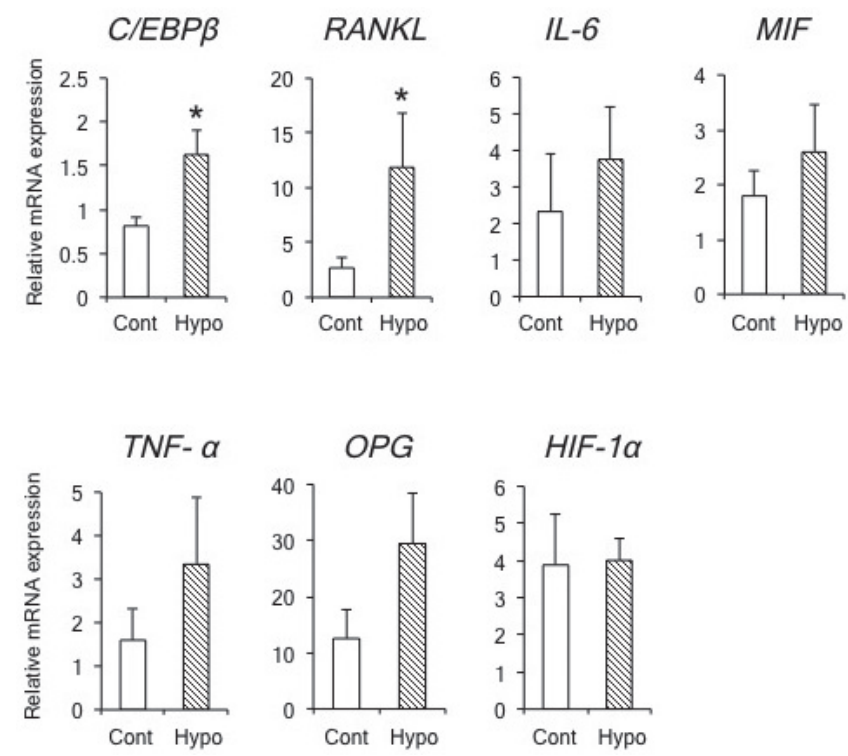

Fig. 1 Gene expressions of C/EBP $\beta$, RANKL, IL-6, MIF, TNF- $\alpha$, OPG, and HIF-1 $\alpha$ in PDL cells under normoxia (Cont) or hypoxia (Hypo). Cells were incubated under either normoxic $\left(\mathrm{O}_{2}: 20 \%\right)$ or hypoxic $\left(\mathrm{O}_{2}\right.$ : less than $\left.0.1 \%\right)$ condition for $24 \mathrm{~h}$, and the gene expressions were examined with RT-qPCR as described in the Materials and Methods section. The data are presented as mean \pm SEM. The asterisks indicate a significant difference $(P<0.05$, Student's $t$-test $)$ in the expression level from the control group.

hydroxylase (PHD), under a normoxic condition. DMOG was dissolved in dimethyl sulfoxide (DMSO) in advance, and $35 \mu \mathrm{L}$ of the DMOG solution was added to $2 \mathrm{~mL}$ of $\alpha$-MEM in each well of six-well dishes. Control PDL cells were cultured in $\alpha$-MEM that contained DMSO but not DMOG under a normoxic condition. After $24 \mathrm{~h}$ incubation, western blotting was carried out to evaluate the HIF- $1 \alpha$ protein level, and RT-qPCR was performed to evaluate the expression of $\mathrm{C} / \mathrm{EBP} \beta$ and RANKL mRNAs.

\section{SiRNA transfection}

To suppress the expression of C/EBP $\beta$ in PDL cells, a predesigned C/EBP $\beta$ siRNA was introduced using a forward transfection method. $\alpha$-MEM used for maintaining the PDL cell culture was replaced with Opti-MEM-I Reduced Serum Medium (Thermo Fisher Scientific). After incubation for $30 \mathrm{~min}$, the cells were washed and transfected with $\mathrm{C} / \mathrm{EBP} \beta$ Silencer Select Pre-Designed siRNA (Forward 5'-GUA UAU UUU GGG AAU CUU Utt-3' Reverse 5'-AAA GAU UCC CAA AAU AUA Cag-3') (Ambion, Carlsbad, CA, USA) or $2 \mu \mathrm{M}$ Stealth RNAi siRNA Negative Control (Thermo Fisher Scientific) in the presence of Lipofectamine RNAiMAX Transfection Reagent (Thermo Fisher Scientific). For testing the efficacy of RNA interference, 0.2-2.0 $\mu \mathrm{M} \mathrm{C} / \mathrm{EBP} \beta$ siRNA was introduced to PDL cells and the expression of $\mathrm{C} / \mathrm{EBP} \beta$ mRNA was measured
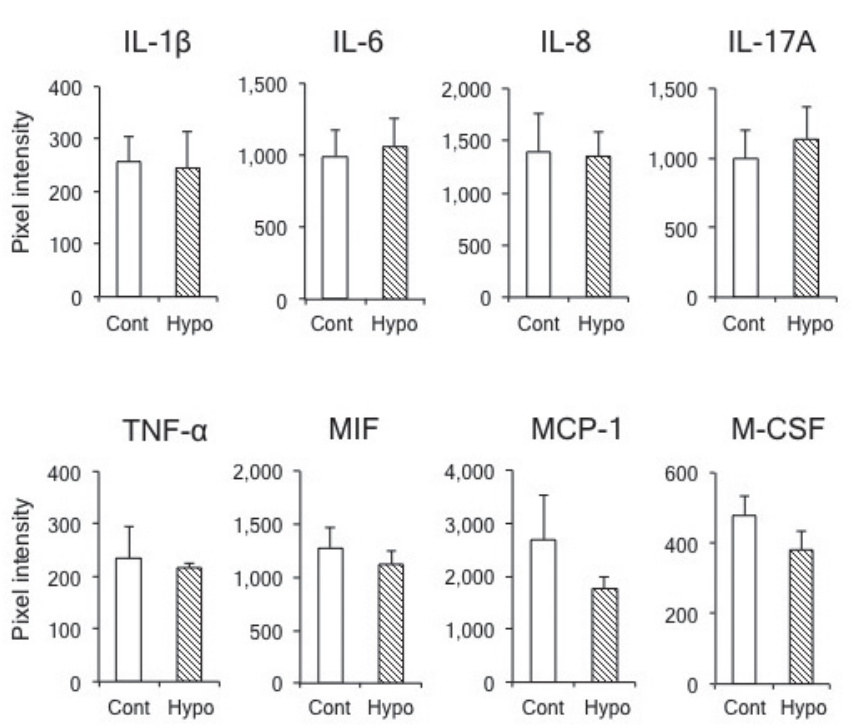

Fig. 2 Protein levels of cytokines secreted by PDL cells under normoxia (Cont) or hypoxia (Hypo). IL-1 $\beta$, IL-6, IL-8, IL-17A, TNF- $\alpha$, MIF, MCP-1, and M-CSF in the culture medium were examined by a cytokine array. Pixel intensity was analyzed using ImageQuant software. The data are presented as the mean \pm SEM. None of these cytokines showed a significant difference in their expression between the Cont and Hypo groups.

with RT-qPCR after $24 \mathrm{~h}$ incubation under normoxia. For testing the effects of the C/EBP $\beta$ siRNA transfection on the expression of RANKL mRNA, $2.0 \mu \mathrm{M} \mathrm{C} / \mathrm{EBP} \beta$ siRNA was introduced to the cells. After $5 \mathrm{~h}$ incubation with the siRNAs, the culture medium was replaced with $\alpha$-MEM supplemented with $10 \%$ FBS, and the cells were cultured for $24 \mathrm{~h}$ under hypoxia. The expression of RANKL mRNA was analyzed with RT-qPCR.

\section{Statistical analysis}

All data were presented as mean \pm standard error of measurement (SEM). Statistical significance was calculated using either a Student's $t$-test or Mann-Whitney $U$ test for pairwise comparisons and Tukey's HSD test for multiple comparisons. $P<0.05$ was considered statistically significant.

\section{Results}

\section{C/EBPß and RANKL mRNA expressions in the PDL} cells exposed to hypoxia

Expression levels of $\mathrm{C} / \mathrm{EBP} \beta$ and RANKL mRNAs increased significantly in PDL cells exposed to hypoxia $(P<0.05)$. By contrast, the mRNA expression of IL-6, macrophage migration inhibitory factor (MIF), TNF- $\alpha$, OPG, and HIF- $1 \alpha$ did not show a change after exposure to hypoxia (Fig. 1). 
A
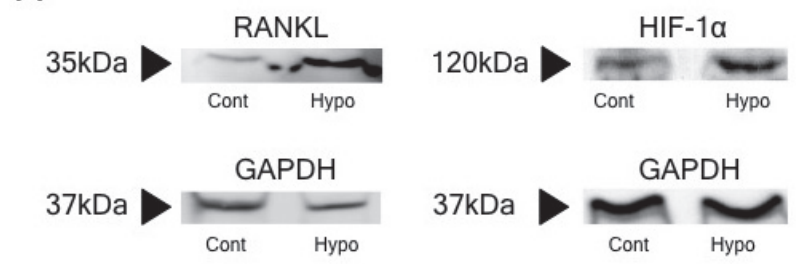

$37 k D a$

GAPDH

B
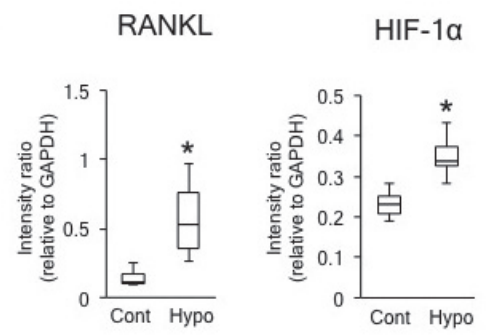

Fig. 3 Western blot analysis for RANKL and HIF-1 $\alpha$ protein expressions in PDL cells cultured for $24 \mathrm{~h}$ under the normoxic (Cont) or hypoxic (Hypo) condition. (A) Representative western blot images of RANKL and HIF-1 $\alpha$ protein expression in the PDL cells. (B) Hypoxia enhanced both RANKL and HIF-1 $\alpha$ protein expressions in the PDL cells. The asterisks indicate a significant difference $(P<0.05$, Mann-Whitney $U$ test $)$ in the expression level from the control group.

\section{Secretion of cytokines from the PDL cells exposed to hypoxia}

Protein levels of IL-1 $\beta$, IL-6, IL-8, IL-17A, M-CSF, MIF, MCP-1, and TNF- $\alpha$ in the cell culture media were evaluated by using Human XL Cytokine Array. None of these eight cytokines showed a significant change in the protein level after exposure to hypoxia (Fig. 2).

\section{Expression of RANKL and HIF-1 $\alpha$ proteins under the hypoxic condition}

The expression of RANKL and HIF- $1 \alpha$ in PDL cells cultured under the hypoxic condition was compared with that in the control PDL cells. Western blotting revealed that the expression of both RANKL and HIF- $1 \alpha$ was increased in the PDL cells exposed to hypoxia (Fig. 3).

\section{Expression and localization of RANKL and HIF-1a in the PDL cells}

Immunofluorescence staining revealed that RANKL and HIF-1 $\alpha$ were expressed predominantly in the nucleus of PDL cells (Fig. 4A), and hypoxia enhanced their expression levels in both nucleus and cytoplasm as indicated with the change in fluorescence intensity ratio (Fig. 4B, C).

\section{Effects of DMOG on HIF-1 $\alpha$ protein and C/EBP and RANKL mRNA expressions}

Incubation of the PDL cells in $\alpha$-MEM supplemented
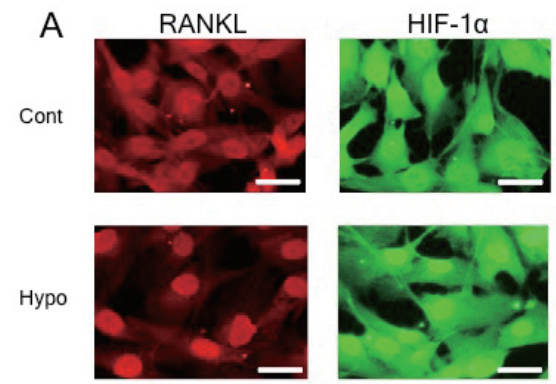

B
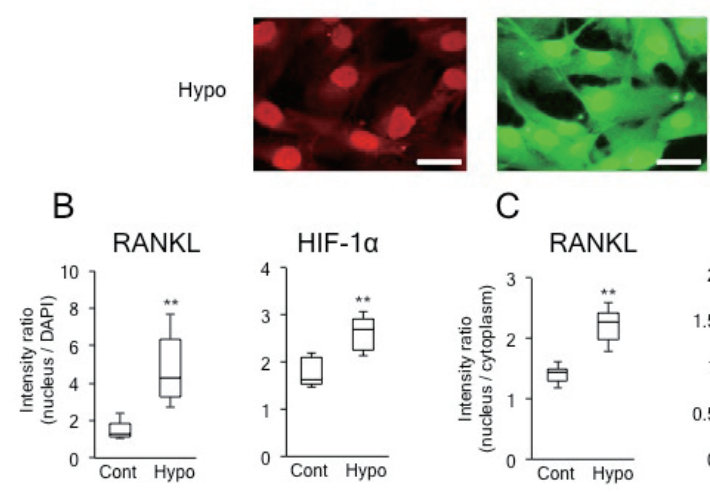

C

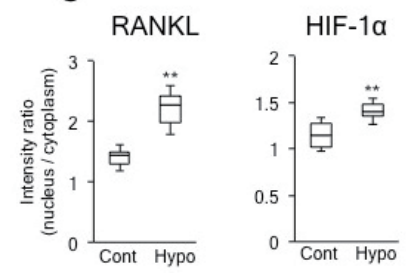

Fig. 4 Immunofluorescence staining of RANKL and HIF-1 $\alpha$ in the PDL cells exposed to normoxia (Cont) or hypoxia (Hypo). (A) Representative images of the PDL cells immunostained for RANKL or HIF-1 $\alpha$. Nuclear DNA of the cells was labeled with DAPI (data not shown), and the fluorescence intensity was used to calculate the intensity ratio. Scale bar: $20 \mu \mathrm{m}$. (B) Hypoxia significantly enhanced the RANKL and HIF-1 $\alpha$ expressions in the nucleus under hypoxia. (C) Hypoxia significantly enhanced the RANKL and HIF-1 $\alpha$ expressions in the cytoplasm under hypoxia. The double asterisks indicate a significant difference $(P<0.001$, Mann-Whitney $U$ test $)$ in the expression level from the control group. For the calculation of intensity ratio, 15 cells were selected randomly from each group.

with $1 \mathrm{mM}$ DMOG increased the HIF-1 $\alpha$ expression under the normoxic condition (Fig. 5A, B). The expression of C/EBP $\beta$ and RANKL mRNAs in PDL cells was significantly increased with the DMOG treatment (Fig. $5 \mathrm{C})$.

\section{Effects of C/EBP $\beta$ siRNA on RANKL mRNA expression under hypoxic condition}

The ability of the C/EBP $\beta$ siRNA to silence the expression of $C / E B P \beta$ mRNA in PDL cells was initially tested. PDL cells transfected with the C/EBP $\beta$ siRNA and cultured under the hypoxic condition showed suppression of the expression of C/EBP $\beta$ mRNA at a dose of $2.0 \mu \mathrm{M}$ (Fig. 6A). PDL cells transfected with $2.0 \mu \mathrm{M} \mathrm{C} / \mathrm{EBP} \beta$ siRNA and cultured under the hypoxic condition revealed that the RANKL mRNA expression in PDL cells was significantly reduced with the C/EBP $\beta$ siRNA (Fig. 6B).

\section{Discussion}

In this study, $\mathrm{C} / \mathrm{EBP} \beta$ is involved in the signaling pathway of the hypoxia-induced up-regulation of RANKL expression in cultured human PDL cells. C/EBP $\beta$, a member of the leucine zipper family of transcription factors, regulates the expression of various genes involved in 
A

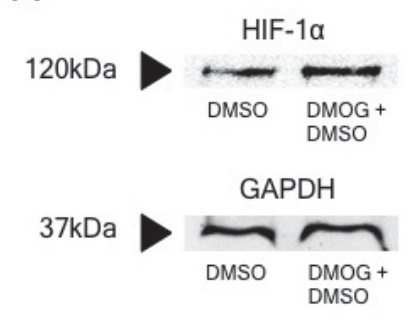

B

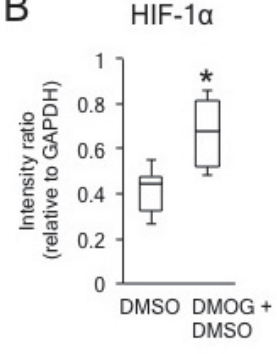

C

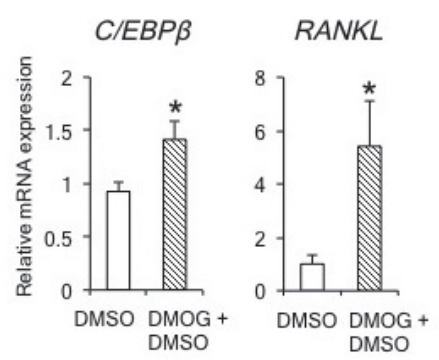

Fig. 5 Effects of DMOG $(1 \mathrm{mM})$ on the expressions of HIF-1 $\alpha$ protein and C/EBP $\beta$ and RANKL mRNAs in PDL cells cultured under the normoxic condition. (A) Representative western blot images of HIF-1 $\alpha$ protein expression in PDL cells cultured with or without DMOG. (B) Western blot analysis for the HIF-1 $\alpha$ protein expression in PDL cells cultured with or without DMOG. (C) Expression levels of $\mathrm{C} / \mathrm{EBP} \beta$ and RANKL mRNAs in PDL cells cultured with or without DMOG. The data are presented as the mean \pm SEM. The asterisks indicate a significant difference $(P<0.05$, B: MannWhitney $U$ test, C: Student's $t$-test).

cell differentiation, proliferation, and tumor progression (25). C/EBP $\beta$ stimulates the expression of matrix metalloproteinase 13 in chondrocytes in inflammatory arthritis (26) and promotes osteoclast formation by increasing the RANKL/OPG mRNA ratio in rheumatoid arthritis synoviocytes (22). C/EBP $\beta$ is up-regulated in giant cell tumor of bone and regulates RANKL expression (27). Our study shows, for the first time, that the C/EBP $\beta$ mRNA expression increases significantly after exposure to hypoxia in PDL cells, and siRNA knockdown of C/EBP $\beta$ strongly decreases the expression of RANKL mRNA in PDL cells. The hypoxia-induced up-regulation of C/EBP $\beta$ mRNA is dependent on the activity of the HIF-1 protein that survives hydroxylation by an $\mathrm{O}_{2}$-dependent enzyme PHD (28). The increase of C/EBP $\beta$ and RANKL mRNAs after the chemical inhibition of PHD with DMOG in the PDL cells in our study further supports the presence of a HIF-1 signaling cascade that mediates up-regulation of C/EBP $\beta$ and RANKL under hypoxic condition (Fig. 7).

Previous reports have shown that human PDL cells respond to hypoxia by increasing the production of various cytokines $(14,18-20,29)$. Hypoxia-augmented lipopolysaccharide-induced cytokine expression in PDL cells (29) and the protein production and mRNA
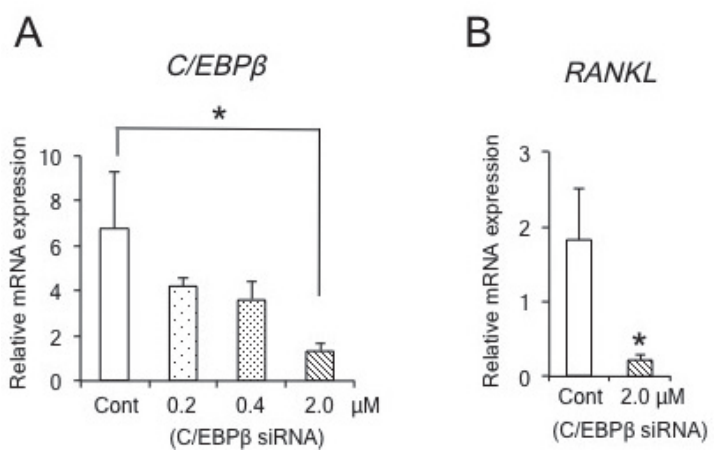

Fig. 6 Effects of $\mathrm{C} / \mathrm{EBP} \beta$ suppression with siRNA transfection in PDL cells. (A) The expression of C/EBP $\beta$ mRNA in PDL cells transfected with a specific C/EBP $\beta$ siRNA or a negative-control (Cont) siRNA and cultured under the normoxic condition for $24 \mathrm{~h}$. The asterisk indicates a significant difference $(P<0.05$, Tukey's HSD test). (B) The expression of RANKL mRNA in the PDL cells transfected with the C/EBP $\beta$ or Cont siRNA and cultured under the hypoxic condition for $24 \mathrm{~h}$. The asterisk indicates a significant difference $(P<0.05$, Student's $t$-test). The data are presented as the mean \pm SEM.

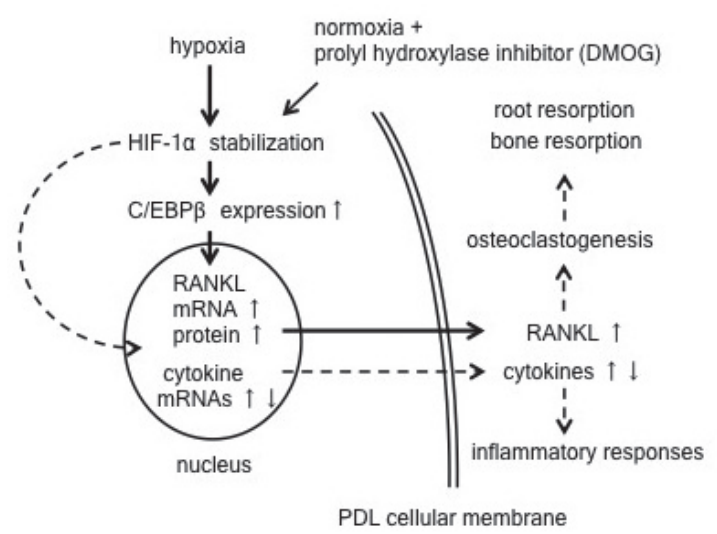

Fig. 7 Proposed signaling pathway of HIF- $1 \alpha$-induced up-regulation of C/EBP $\beta$ and RANKL in PDL cells. HIF- $1 \alpha$ stabilization enhanced RANKL mRNA and protein via both up-regulation of the C/EBP $\beta$ expression and direct transcriptional activation of the RANKL gene. In addition, HIF- $1 \alpha$ stabilization up- or down-regulated the expression of various cytokines implicated in inflammatory responses.

expression of IL-1 $\beta$ and IL- 6 were up-regulated in the culture of human PDL cells exposed to hypoxia (14). The secretion of IL-1 $\beta$, IL-6, IL-8, IL-17A, TNF- $\alpha$, MIF, MCP-1, and M-CSF in the culture media of PDL cells exposed to hypoxia were measured, and none of these secreted cytokines shows a change in their protein levels in response to hypoxia. Among these cytokines, protein levels of IL- $1 \beta$ and TNF- $\alpha$ in the culture media are near the detection limits (data not shown) in our study. There is no difference in the expression of IL-6, TNF- $\alpha$, and MIF mRNAs between the hypoxia-exposed cells and control cells. The apparent discrepancy concerning the effects of hypoxia on the expression of IL-1 $\beta$ and IL- 6 in 
PDL cells may be due to the difference of the origin of the cells. In this study, immortalized cells derived from human deciduous teeth (23) are used, whereas the other research group used primary cells derived from human permanent molars (14).

RANKL is an osteoblast/stromal cell-derived factor that is essential for osteoclastogenesis $(7,9,12)$, and exposure of PDL fibroblasts to hypoxia or overexpression of constitutively active HIF- $1 \alpha$ in the fibroblasts significantly increases RANKL promoter activity $(18,19)$. Hypoxia-induced RANKL expression that is mediated by HIF-1 $\alpha$ activation has been reported in breast cancer cells as well (30). The present study suggests that pharmacological suppression of the expression of $\mathrm{C} / \mathrm{EBP} \beta$ or RANKL may be effective for inhibiting tooth root resorption and resorption of supporting bone in case of a traumatic injury of PDL tissues. It has been reported that PDL cells synthesize both RANKL and OPG and that inactivation of OPG may play a key role in osteoclastogenesis (11). OPG mRNA expression in the PDL cells is not influenced by exposure to hypoxia in this study. Therefore, applying stable OPG homologues to PDL tissues exposed to hypoxia may be an alternative to preventing pathological tooth root resorption.

In conclusion, the present study demonstrates that the $\mathrm{C} / \mathrm{EBP} \beta$-mediated signaling cascade is involved in hypoxia-induced RANKL expression in PDL cells. In addition, stabilization of HIF- $1 \alpha$ protein is crucial for the transcriptional activation of the $\mathrm{C} / \mathrm{EBP} \beta$ gene under hypoxic conditions. $\mathrm{C} / \mathrm{EBP} \beta$ may play an important role in tooth root resorption and alveolar bone resorption via RANKL activation after traumatic injuries.

\section{Acknowledgments}

This study was supported by a Grant-in-Aid for Scientific Research from the Japanese Society for the Promotion of Science (JSPS KAKENHI 26463120); a Health Labour Sciences Research Grant from the Ministry of Health, Labour and Welfare (10201010); MEXT-Supported Program for the Strategic Research Foundation at Private Universities 2010-2014 from the Ministry of Education, Culture, Sports, Science, and Technology, Japan; and research grants from the Dental Research Center and Sato Funds from Nihon University School of Dentistry.

\section{Conflict of interest}

The authors have no conflict of interest to declare.

\section{References}

1. Groeneveld MC, Everts V, Beertsen W (1995) Alkaline phosphatase activity in the periodontal ligament and gingiva of the rat molar: its relation to cementum formation. J Dent Res 74, 1374-1381.
2. Kinoshita S, Mitomi T, Taguchi Y, Noda T (2000) Prognosis of replanted primary incisors after injuries. Endod Dent Traumatol 16, 175-183.

3. Harokopakis-Hajishengallis E (2007) Physiologic root resorption in primary teeth: molecular and histological events. J Oral Sci 49, 1-12.

4. Moule AJ, Moule CA (2007) The endodontic management of traumatized permanent anterior teeth: a review. Aust Dent $\mathrm{J}$ 52, S122-S137.

5. Polson AM, Caton J (1982) Factors influencing periodontal repair and regeneration. J Periodontol 53, 617-625.

6. Sasaki T (2003) Differentiation and functions of osteoclasts and odontoclasts in mineralized tissue resorption. Microsc Res Tech 61, 483-495.

7. Simonet WS, Lacey DL, Dunstan CR, Kelley M, Chang MS, Lüthy R et al. (1997) Osteoprotegerin: a novel secreted protein involved in the regulation of bone density. Cell 89, 309-319.

8. Lacey DL, Timms E, Tan HL, Kelley MJ, Dunstan CR, Burgess T et al. (1998) Osteoprotegerin ligand is a cytokine that regulates osteoclast differentiation and activation. Cell 93, 165-176.

9. Yasuda H, Shima N, Nakagawa N, Yamaguchi K, Kinosaki M, Mochizuki S et al. (1998) Osteoclast differentiation factor is a ligand for osteoprotegerin/osteoclastogenesis-inhibitory factor and is identical TRANCE/RANKL. Proc Natl Acad Sci USA 95, 3597-3602.

10. Yasuda H, Shima N, Nakagawa N, Mochizuki SI, Yano K, Fujise $\mathrm{N}$ et al. (1998) Identity of osteoclastogenesis inhibitory factor (OCIF) and osteoprotegerin (OPG): a mechanism by which OPG/OCIF inhibits osteoclastogenesis in vitro. Endocrinology 139, 1329-1337.

11. Hasegawa T, Yoshimura Y, Kikuiri T, Yawaka Y, Takeyama S, Matsumoto A et al. (2002) Expression of receptor activator of NF-kappa B ligand and osteoprotegerin in culture of human periodontal ligament cells. J Periodontal Res 37, 405-411.

12. Romas E, Gillespie MT, Martin TJ (2002) Involvement of receptor activator of NFKB ligand and tumor necrosis factoralpha in bone destruction in rheumatoid arthritis. Bone 30, 340-346.

13. Kim MS, Day CJ, Morrison NA (2005) MCP-1 is induced by receptor activator of nuclear factor- $\mathrm{kB}$ ligand, promotes human osteoclast fusion, and rescues granulocyte macrophage colony-stimulating factor suppression of osteoclast formation. J Biol Chem 280, 16163-16169.

14. Motohira H, Hayashi J, Tatsumi J, Tajima M, Sakagami H, Shin K (2007) Hypoxia and reoxygenation augment boneresorbing factor production from human periodontal ligament cells. J Periodontol 78, 1803-1809.

15. Benatti BB, Silvério KG, Casati MZ, Sallum EA, Nociti FH Jr (2009) Inflammatory and bone-related genes are modulated by aging in human periodontal ligament cells. Cytokine 46, 176-181.

16. Kikuiri T, Yoshimura Y, Tabata F, Hasegawa T, Nishihira J, Shirakawa T (2012) Stage-dependent suppression of the 
formation of dentin-resorbing multinuclear cells with migration inhibitory factor in vitro. Exp Ther Med 3, 37-43.

17. Cai Z, Falkensammer F, Andrukhov O, Chen J, Mittermayr R, Rausch-Fan X (2016) Effects of shock waves on expression of IL-6, IL-8, MCP-1, and TNF- $\alpha$ expression by human periodontal ligament fibroblasts: an in vitro study. Med Sci Monit 22, 914-921.

18. Park HJ, Baek KH, Lee HL, Kwon A, Hwang HR, Qadir AS et al. (2011) Hypoxia inducible factor- $1 \alpha$ directly induces the expression of receptor activator of nuclear factor- $\mathrm{\kappa}$ ligand in periodontal ligament fibroblasts. Mol Cells 31, 573-578.

19. Gölz L, Memmert S, Rath-Deschner B, Jäger A, Appel T, Baumgarten G et al. (2015) Hypoxia and P. gingivalis synergistically induce HIF-1 and NF- $\mathrm{kB}$ activation in PDL cells and periodontal diseases. Mediators Inflamm doi, $10.1155 / 2015 / 438085$.

20. Yu XJ, Xiao CJ, Du YM, Liu S, Du Y, Li S (2015) Effect of hypoxia on the expression of RANKL/OPG in human periodontal ligament cells in vitro. Int J Clin Exp Pathol 8, 12929-12935.

21. Akira S, Isshiki H, Sugita T, Tanabe O, Kinoshita S, Nishio Y et al. (1990) A nuclear factor for IL-6 expression (NF-IL6) is a member of a C/EBP family. EMBO J 9, 1897-1906.

22. Tsushima H, Okazaki K, Ishihara K, Ushijima T, Iwamoto $Y$ (2015) CCAAT/enhancer-binding protein $\beta$ promotes receptor activator of nuclear factor-kappa-B ligand (RANKL) expression and osteoclast formation in the synovium in rheumatoid arthritis. Arthritis Res Ther, doi. 10.1186/s13075-015-0532-6.

23. Hasegawa T, Chosa N, Asakawa T, Yoshimura Y, Ishisaki A, Tanaka M (2010) Establishment of immortalized human periodontal ligament cells derived from deciduous teeth. Int J Mol Med 26, 701-705.

24. Aukkarasongsup P, Haruyama N, Matsumoto T, Shiga M, Moriyama K. (2013) Periostin inhibits hypoxia-induced apoptosis in human periodontal ligament cells via TGF- $\beta$ signaling. Biochem Biophys Res Commun 441, 126-132.

25. Nerlov C (2007) The C/EBP family of transcription factors: a paradigm for interaction between gene expression and proliferation control. Trends Cell Biol 17, 318-324.

26. Hayashida M, Okazaki K, Fukushi J, Sakamoto A, Iwamoto Y (2009) CCAAT/enhancer binding protein $\beta$ mediates expression of matrix metalloproteinase 13 in human articular chondrocytes in inflammatory arthritis. Arthritis Rheum 60, 708-716.

27. Ng PK, Tsui SK, Lau CP, Wong CH, Wong WH, Huang L et al. (2010) CCAAT/enhancer binding protein beta is up-regulated in giant cell tumor of bone and regulates RANKL expression. J Cell Biochem 110, 438-446.

28. Zhdanov AV, Okkelman IA, Collins FW, Melgar S, Papkovsky DB (2015) A novel effect of DMOG on cell metabolism: direct inhibition of mitochondrial function precedes HIF target gene expression. Biochim Biophys Acta 1847, 1254-1266.

29. Jian C, Li C, Ren Y, He Y, Li Y, Feng X et al. (2014) Hypoxia augments lipopolysaccharide-induced cytokine expression in periodontal ligament cells. Inflammation 37, 1413-1423.

30. Tang ZN, Zhang F, Tang P, Qi XW, Jiang J (2011) Hypoxia induces RANK and RANKL expression by activating HIF- $1 \alpha$ in breast cancer cells. Biochem Biophys Res Commun 408, 441-416. 